\title{
MYC is expressed in the stromal and epithelial cells of primary breast carcinoma and paired nodal metastases
}

\author{
FIORITA GONZALES LOPES MUNDIM ${ }^{1}$, FATIMA SOLANGE PASINI ${ }^{2}$, MARIA MITZI BRENTANI ${ }^{2,3}$, \\ FERNANDO AUGUSTO SOARES ${ }^{3}$, SUELY NONOGAKI ${ }^{3}$ and ANGELA FLÁVIA LOGULLO WAITZBERG ${ }^{1}$ \\ ${ }^{1}$ Department of Pathology, Federal University of São Paulo, São Paulo, SP 04023-900; \\ ${ }^{2}$ Department of Radiology and Oncology (LIM24), Medical School of São Paulo University, São Paulo, SP 01246-903; \\ ${ }^{3}$ Department of Pathology, A.C. Camargo Hospital, São Paulo, SP 01509-010, Brazil
}

Received October 24, 2012; Accepted February 11, 2015

DOI: $10.3892 / \mathrm{mco} .2015 .526$

\begin{abstract}
The MYC oncogene is directly involved in the proliferation, metabolism, progression and distant metastasis of breast cancer. Since metastatic spread to the lymph nodes is often the first indication of propensity for metastatic dissemination, the MYC status in nodal disease may represent a decision-making variable. However, the analysis of MYC expression in stromal cells, namely cancer-associated fibroblasts (CAFs), which are known to play a critical role in cancer progression, remains poorly reported. The aim of this study was to determine the expression of MYC and other markers, including estrogen receptor (ER), progesterone receptor (PR), human epidermal growth factor receptor 2 (HER2), p53, Ki67, epidermal growth factor receptor (EGFR), phosphorylated AKT (p-AKT) and phospho-mammalian target of rapamycin (p-mTOR) by immunohistochemistry in representative samples from 80 patients with ductal infiltrative breast cancer and 43 paired compromised axillary lymph nodes allocated in tissue microarrays (TMAs). The epithelial and stromal components of primary tumors and respective lymph node metastases were separately analyzed. MYC expression (cytoplasmic and nuclear) was a frequent event in the epithelial and stromal components of the primary tumors. The epithelial cells in the nodal metastases exhibited a trend for decreased MYC expression compared to that in the primary tumors $(\mathrm{P}=0.08)$ but retained the original status of the primary tumors for all other markers. The stromal cells were uniformly negative for ER, PR, HER2, p53, Ki67 and EGFR. Comparison of the stromas of primary tumors and respective lymph node metastases revealed a reduced frequency of nuclear MYC in 15\%
\end{abstract}

Correspondence to: Professor Maria Mitzi Brentani, Department of Radiology and Oncology (LIM24), Medical School of São Paulo University, 455 Dr Arnaldo Avenida, $4^{\circ}$ Andar, Sala 4115, Cerqueira César, São Paulo, SP 01246-903, Brazil

E-mail: mbrentani@lim24.fm.usp.br

Key words: MYC, breast carcinoma, cancer-associated fibroblasts, nodal metastasis, proliferation markers of the cases $(\mathrm{P}=0.003)$, whereas $\mathrm{p}$-mTOR followed a similar trend $(\mathrm{P}=0.09)$. Analyses of the possible correlations among markers revealed that epithelial nuclear MYC was associated with p53 $(\mathrm{P}=0.048)$. This is an original study demonstrating a significant proportion of MYC expression (nuclear or cytoplasmic), as well p-mTOR and p-AKT expression, in the epithelial and stromal components of either the primary tumor or the nodal metastases. CAFs expressing MYC may establish an angiogenic microenvironment supporting cancer survival and facilitating colonization at the nodal metastatic site.

\section{Introduction}

The MYC oncogene, which encodes a transcription factor, is directly involved in several processes that regulate cell fate. Therefore, MYC is expected to be functionally deregulated in several human neoplasias as a result of genetic and epigenetic alterations (1). As one of the first genes found to be amplified in a significant proportion (8-37\%) of breast cancer cases, MYC is considered to promote cell survival, proliferation, apoptosis, differentiation inhibition and progression in breast cancer, all of which may indirectly contribute to metastasis $(2,3)$.

There is a general consensus that MYC amplification is a characteristic of aggressive breast cancer and a recent study reported that MYC regulates the expression of 13 different poor outcome cancer signatures (4). Since lymph node status is an important factor in breast cancer staging and therapeutic options, the MYC status in compromised lymph nodes may represent a potential decision-making variable. MYC amplification and immunohistochemical staining were reported as being independent predictors of lymph node metastasis, but other studies did not report such a correlation (5-7).

Although detailed biomarker profiles of the metastatic lesions of breast carcinomas are scarce in the literature, certain studies report a high incidence of MYC overexpression/amplification in the distant metastases of invasive ductal carcinoma $(6,8,9)$. However, whether the MYC status may change in lymph node metastases compared to that in the corresponding primary breast tumor has not been clearly determined.

Accumulating evidence suggests that peritumoral microenvironment and tumor interactions play a critical role in breast cancer growth and dissemination. Specifically activated 
fibroblasts [cancer-associated fibroblasts (CAFs)] that are recruited into cancer tissue, are potential promoters of tumor progression (10). However, the MYC status in the stromal cells of the breast tumor microenvironment, namely the CAFs, as well in corresponding nodal metastases, has not been extensively investigated.

The aim of the present study was to assess the expression of MYC in CAFs and epithelial tumor cells in samples of primary infiltrative breast carcinomas and paired compromised lymph nodes represented on tissue microarrays (TMAs). These data were correlated with clinical parameters and also with the expression of other markers associated with breast cancer proliferation, such as Ki67, phospho-mammalian target of rapamycin (p-mTOR), phospho-AKT (p-AKT), p53, epidermal growth factor receptor (EGFR), as well as classic predictive markers, such as estrogen receptor (ER), progesterone receptor (PR) and human epidermal growth factor receptor 2 (HER2) receptor. We also aimed to assess whether the expression of these biological markers, either in CAFs or in tumor epithelial cells, may change in the nodal metastases compared to the corresponding primary breast cancer.

\section{Patients and methods}

Patients. We retrospectively analyzed 80 cases of patients with primary invasive breast ductal carcinoma not otherwise specified, who underwent surgery at the Hospital Samuel Libânio (Pouso Alegre, MG, Brazil) between 1997 and 2005. The mean age of the patients was 57 years (range, 23-88 years). All the cases were reviewed in relation to demographic and clinicopathological data. This study was approved by the Institutional Ethics Committee of the Hospital Samuel Libânio. The 80 suitable samples from selected cases were submitted to immunohistochemical reactions and analysis through the technique of TMA. The characteristics of the study population are summarized in Table I.

The inclusion criteria were as follows: Patients with available clinical data and with paraffin blocks and histological slides suitable for immunohistochemical reevaluation. Cases with inaccessible information were excluded. The inability to obtain information involved different stages, such as medical record not retrieved, insufficient clinical data, women who received any treatment prior to surgery for breast cancer, paraffin block not retrieved, deteriorated sample, lack of material representative of the tumor pathology and cases with carcinoma in situ and other malignancies of the breast.

Construction of TMA. Samples from each tumor were allocated in three distinct sets of TMAs. The first exclusively contained areas of epithelial tumor component. The second TMA was built with samples of the stromal component of the tumor, in order to enable the assessment of stromal cells within the desmoplastic contingent of the carcinomas. The third TMA involved 43 cases with lymph node metastasis, with samples selected from the metastastic lesion of the major compromised lymph node.

Following preparation of the TMA blocks, 3-mm sections were collected on slides with special adhesives (Instrumedics, Inc., San Diego, CA, USA). The TMA was constructed using the Manual Tissue Arrayer I (Beecher Instruments, Inc., Sun Prairie, WI, USA).
Table I. Clinicopathological parameters of breast cancer patients $(n=80)$.

\begin{tabular}{|c|c|}
\hline Characteristics & No. $(\%)$ \\
\hline Age, years [median (range)] & $57(23-88)$ \\
\hline \multicolumn{2}{|l|}{ Hormonal status } \\
\hline Premenopausal & $21(26.2)$ \\
\hline Postmenopausal & $59(73.8)$ \\
\hline \multicolumn{2}{|l|}{ Clinical stage } \\
\hline $\mathrm{I}$ & $20(25.0)$ \\
\hline II & $32(40.0)$ \\
\hline III & $28(35.0)$ \\
\hline \multicolumn{2}{|l|}{ Mastectomy } \\
\hline No & $33(41.3)$ \\
\hline Yes & $46(57.5)$ \\
\hline Missing & $1(1.2)$ \\
\hline \multicolumn{2}{|l|}{ Involved margins } \\
\hline Absent & $15(18.8)$ \\
\hline Present & $65(81.2)$ \\
\hline \multicolumn{2}{|l|}{ Necrosis } \\
\hline Absent & $37(46.2)$ \\
\hline Present & $43(53.8)$ \\
\hline \multicolumn{2}{|l|}{ Desmoplasia } \\
\hline Yes & $80(100.0)$ \\
\hline \multicolumn{2}{|l|}{ Lymph node status } \\
\hline pN0 & $37(46.2)$ \\
\hline $\mathrm{pN}+$ & $43(53.8)$ \\
\hline \multicolumn{2}{|l|}{ Histological grade } \\
\hline $\mathrm{I}$ & $18(22.5)$ \\
\hline II & $29(36.3)$ \\
\hline III & $33(41.2)$ \\
\hline \multicolumn{2}{|l|}{ Nuclear grade } \\
\hline 1 & $6(7.5)$ \\
\hline 2 & $38(47.5)$ \\
\hline 3 & $36(45.0)$ \\
\hline \multicolumn{2}{|l|}{ Tubular differentiation } \\
\hline 1 & $3(3.8)$ \\
\hline 2 & $26(32.5)$ \\
\hline 3 & $51(63.7)$ \\
\hline \multicolumn{2}{|l|}{ Tumor size } \\
\hline $\mathrm{T} 1$ & $36(45.0)$ \\
\hline $\mathrm{T} 2$ & $34(42.5)$ \\
\hline $\mathrm{T} 3$ & $6(7.5)$ \\
\hline Missing & $4(5.0)$ \\
\hline \multicolumn{2}{|l|}{ Mitoses } \\
\hline $0-5$ & $32(40.0)$ \\
\hline$>5$ & $48(60.0)$ \\
\hline
\end{tabular}

Immunohistochemistry. Two slides from each TMA block, with sections on two levels and $\sim 40$ sections between the two, were submitted to immunohistochemical reactions. The immunohistochemical reactions were performed using the 
technique of third-generation polymer (NovoLink Polymer Detection System; Leica Biosystems Newcastle Ltd., Newcastle upon Tyne, UK). Following deparaffinization of the tissue sections, antigen retrieval was performed using a pressure cooker in citrate buffer $(\mathrm{pH}$ 6.0), followed by blocking endogenous peroxidase with $3 \%$ hydrogen peroxide solution. The sections were incubated with the following primary antibodies: IgG2a, $\kappa$ mouse polyclonal MYC (1:50, 9E10.3, MS139, Neomarkers, Thermo Fisher Scientific Inc., Fremont, CA, USA), IgG, rabbit polyclonal c-erbB-2 (1:2,000, A0485; DakoCytomation), IgG1 mouse monoclonal EGFR (1:400, ERGFR.25 clone, NCL-EGFR-384; Novocastra, Newcastle, UK), IgG1, $\kappa$ mouse monoclonal Ki67 (1:200, MIB-1, M7240; DakoCytomation), IgG, rabbit monoclonal ER (1:500, SP1 clone, RM9101; NeoMarkers, Fremont, CA, USA),IgG1, kappa mouse monoclonal PR (1:400, PgR636 clone, M3569; DakoCytomation), IgG rabbit monoclonal p-mTOR (Ser2448) (1:50, 49F9 clone, 2976; Cell Signaling Technology, Inc., Beverly, MA, USA), IgG2b, monoclonal p-AkT (Ser473) (1:800, 587F11 clone, 4051; Cell Signaling Technology Inc.) and $\mathrm{IgG} 2 \mathrm{~b}, \kappa$ monoclonal mouse p53 (1:100, DO7 clone, M7001; DakoCytomation). Subsequently, the slides were incubated with Post Primary Block, followed by incubation with NovoLink Polymer HRP (RE7140-K; Leica Microsystems Newcastle Ltd., Newcastle upon Tyne, UK). The reactions were visualized with diaminobenzidine (liquid DAB + substrate kit, K3468; DakoCytomation) and counterstained with Harris's hematoxylin (Merck KGaA, Darmstadt, Germany).

All the reactions were assessed and described separately by two independent observers who were blinded to the clinical data. Disparities between the two pathologists (AFLW and FGLM) were resolved by consensus. Results from the epithelial and stromal components were reported separately for primary carcinomas and lymph node samples. MYC expression was independently assessed in the nucleus and the cytoplasm and was considered to be positive when $>10 \%$ of the cells were stained. EGFR and HER2 were assessed by the HercepTest $^{\mathrm{TM}}$ (DakoCytomation) system considering membranous staining (11). ER, PR and Ki67 were separately assessed in the nucleus of neoplastic epithelial cells and in the stromal cell populations in the primary tumors and lymph node metastases, according to the Allred and Elledge (12) system. p53, p-Akt and p-mTOR, were considered to be positive when the percentage of stained cells was $\geq 10 \%$.

Statistical methods. The correlations between categorical antigen expression and other clinicopathological parameters were assessed with the Fisher's exact test or the Chi-square test, as appropriate. The Spearman's rank correlation coefficient was calculated to assess categorical antigen expression. All the statistical tests were two-sided and significance was set at $\mathrm{P}<0.05$. The analyses were performed using SSPS v. 10.0 software for Windows (SPSS, Inc., Chicago, IL, USA).

\section{Results}

Immunohistochemical analysis results. Taking into consideration that MYC immunostaining may be present within the nuclei or in the cytoplasm and the localization of MYC may affect prognosis in primary breast cancer, cytoplasmatic
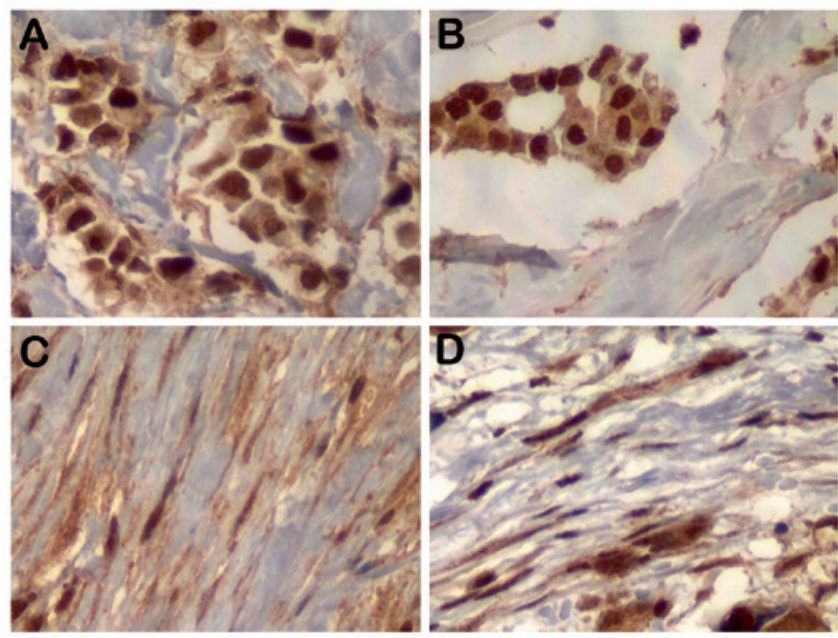

Figure 1. Representative nuclear MYC immunohistochemical staining of (A) tumor epithelial cells and (B) nodal metastasis. MYC staining in the stroma of (C) the matched primary tumor and (D) nodal metastatic breast cancer. Magnification, x400.

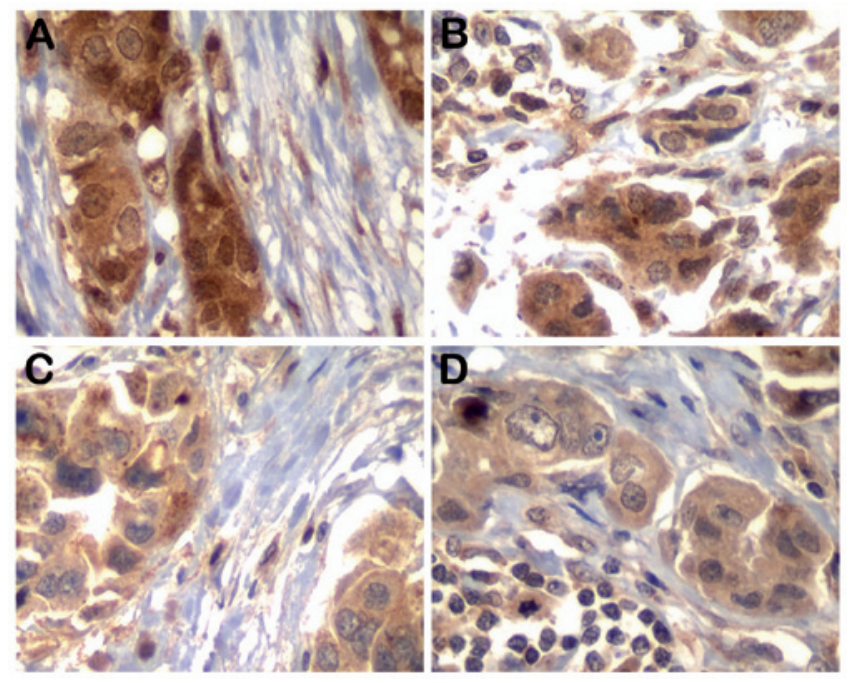

Figure 2. (A and B) Phospho-AKT and (C and D) phospho-mammalian target of rapamycin in the tumor epithelial cells and associated fibroblasts in the matched primary tumors and nodal metastatic disease. Magnification, x400.

and nuclear MYC were scored independently, as previously described (8).

Representative results for MYC, p-AKT and p-mTOR for tumor epithelial cells and associated fibroblasts in primary tumors and nodal disease are shown in Figs. 1 and 2. The results regarding MYC and other biological marker staining frequency as determined by immunohistochemistry in both components of primary tumors are summarized in Table II. After excluding cases with missing data, MYC protein expression (nuclear or cytoplasmic) was present in epithelial and stromal cells of the primary tumors at similar frequencies. Other biological markers were also determined in the epithelial and stromal component of the primary tumors; $42.5 \%$ of the epithelial cells were found to be ER-positive, $36.3 \%$ were PR-positive (13 of the 26 ER-positive cases were PR-negative), $21.3 \%$ were HER2-positive and $31.2 \%$ were p53-positive, while only $3.8 \%$ were EGFR-positive. The stromal cells were uniformly negative 
Table II. Frequencies of c-MYC and other biomarkers in the primary tumor components $(n=80)$.

\begin{tabular}{|c|c|c|}
\hline \multirow[b]{2}{*}{ Markers } & \multicolumn{2}{|c|}{ Primary tumor, no. (\%) } \\
\hline & Epithelium & Stroma \\
\hline \multicolumn{3}{|c|}{ c-MYC (cyt) } \\
\hline Negative & $2(2.5)$ & $3(3.8)$ \\
\hline Positive & $77(96.3)$ & $77(96.2)$ \\
\hline Missing & $1(1.2)$ & $0(0.0)$ \\
\hline \multicolumn{3}{|c|}{ c-MYC (nuc) } \\
\hline Negative & $10(12.5)$ & $5(6.3)$ \\
\hline Positive & $69(86.3)$ & $75(93.7)$ \\
\hline Missing & $1(1.2)$ & $0(0.0)$ \\
\hline \multicolumn{3}{|l|}{ ER } \\
\hline Negative & $44(55.0)$ & $71(88.8)$ \\
\hline Positive & $34(42.5)$ & $0(0.0)$ \\
\hline Missing & $2(2.5)$ & $9(11.2)$ \\
\hline \multicolumn{3}{|l|}{ PR } \\
\hline Negative & $41(51.2)$ & $77(96.2)$ \\
\hline Positive & $29(36.3)$ & $0(0.0)$ \\
\hline Missing & $10(12.5)$ & $3(3.8)$ \\
\hline \multicolumn{3}{|l|}{ HER2 } \\
\hline Negative & $61(76.2)$ & $76(95.0)$ \\
\hline Positive & $17(21.3)$ & $0(0.0)$ \\
\hline Missing & $2(2.5)$ & $4(5.0)$ \\
\hline \multicolumn{3}{|l|}{ EGFR } \\
\hline Negative & $75(93.7)$ & $78(97.5)$ \\
\hline Positive & $3(3.8)$ & $0(0.0)$ \\
\hline Missing & $2(2.5)$ & $2(2.5)$ \\
\hline \multicolumn{3}{|l|}{ p53 } \\
\hline Negative & $49(61.3)$ & $75(93.7)$ \\
\hline Positive & $25(31.2)$ & $0(0.0)$ \\
\hline Missing & $6(7.5)$ & $5(6.3)$ \\
\hline \multicolumn{3}{|l|}{ Ki67 } \\
\hline Negative & $57(71.3)$ & $76(95.0)$ \\
\hline Positive & $17(21.3)$ & $0(0.0)$ \\
\hline Missing & $6(7.4)$ & $4(5.0)$ \\
\hline \multicolumn{3}{|l|}{ mTOR } \\
\hline Negative & $41(51.3)$ & $45(56.2)$ \\
\hline Positive & $38(47.5)$ & 35 (43.8) \\
\hline Missing & $1(1.2)$ & $0(0.0)$ \\
\hline \multicolumn{3}{|l|}{ p-AKT } \\
\hline Negative & $17(21.3)$ & $24(30.0)$ \\
\hline Positive & $63(78.7)$ & $56(70.0)$ \\
\hline Missing & $0(0.0)$ & $0(0.0)$ \\
\hline
\end{tabular}

Cyt, cytoplasmic; nuc, nuclear; EGFR, epidermal growth factor receptor; $\mathrm{p}-\mathrm{AKT}$, phospho-AKT; ER, estrogen receptor; PR, progesterone receptor; HER2, human epidermal growth factor receptor 2; mTOR, mammalian target of rapamycin.

for ER, PR, HER2, p53 and EGFR in the primary tumors. The MIB-1 labeling rate of fibroblasts was always $<10 \%$ and, thus, they were considered as Ki67-negative. Similar frequencies of
p-mTOR and p-AKT positivity were displayed by the epithelial and stromal component of the primary tumors.

To determine whether the biological markers of proliferation were relevant to breast cancer progression, we compared the expression of these proteins in primary tumors and paired metastatic lymph nodes $(n=43)$. In Table III, the detection frequency of biological markers in the primary tumors was compared to their detection in the paired lymph node metastasis, independently analyzing epithelia and stroma. The pattern of nuclear MYC reflected a trend to lower frequency of positive expression in lymph node epithelia compared to that in primary tumors $(\mathrm{P}=0.08)$. The majority of the primary tumors retained their original status regarding the standard markers in the epithelial component of the nodal metastasis. The comparison between the stromal component of the primary tumors and respective lymph nodes revealed a trend for a lower frequency of cytoplasmic MYC $(\mathrm{P}=0.09)$ and p-mTOR ( $\mathrm{P}=0.09)$ expression in the lymph nodes, while the decrease in frequency of nuclear MYC in the nodal stroma was statistically significant $(\mathrm{P}=0.003)$.

We next evaluated whether proliferation markers in the epithelial tissue of primary tumors correlated with prognostic factors and found that Ki67 was statistically associated with high histological grade $(\mathrm{P}=0.02)$, number of mitoses $(\mathrm{P}=0.01)$ and infiltrative margins $(\mathrm{P}=0.05)$, while $\mathrm{p}-\mathrm{AKT}$ expression in the epithelial cells was associated with advanced disease stage ( $\mathrm{P}=0.04$, Table IV). Of note, the $\mathrm{p}-\mathrm{AKT}$ positivity rate in stromal fibroblasts was also associated with advanced stage (data not shown, $\mathrm{P}=0.01$ ).

In order to investigate the association between proliferation markers and molecular subtypes, a surrogate immunohistochemistry-based classifier was used $(13,14)$. Molecular subtypes were defined as luminal $\mathrm{A}\left(\mathrm{ER}^{+}\right.$or $\mathrm{PR}^{+}$, HER2 ${ }^{-}$and $\left.\mathrm{Ki} 67<10 \%\right)$; luminal $\mathrm{B}\left(\mathrm{ER}^{+}\right.$or $\mathrm{PR}^{+}, \mathrm{HER}^{+}$and $\mathrm{Ki} 67 \geq 10 \%$ ) and triple-negative (ER-, $\mathrm{PR}^{-}$and HER2-). A total of 29 tumors were classified as luminal A, $13(18.8 \%)$ as luminal B, 12 as HER2-enriched and 15 as triple-negative. Luminal A tumors exhibited a trend for positivity of MYC (nuclear), as compared to other subgroups $(\mathrm{P}=0.13)$. Ki67 expression frequency was statistically significantly associated with the others groups (Table V).

When analyzing the possible correlations among all the proliferation markers (Table VI) in the epithelial tissues of breast carcinoma, we verified that nuclear MYC was associated with p53 $(\mathrm{p}=0.048)$, which in turn was associated with $\mathrm{Ki67}(\mathrm{P}=0.045)$. ER was positively associated with PR $(\mathrm{P}=0.006)$ and inversely associated with HER2 $(\mathrm{P}=0.002)$. $\mathrm{PR}$ was also inversely associated with HER2 $(\mathrm{P}=0.036)$. There were no significant correlations among the remaining markers.

\section{Discussion}

Metastatic spread to the lymph nodes is one of the predominant routes of breast cancer spread and is often the first indication of propensity for metastatic dissemination $(15,16)$. Progressive tumor growth requires active proliferation of migrating tumor cells at the lymph nodes to develop into an established metastatic tumor (17). Therefore, the elucidation of the mechanism through which cancer cells permanently colonize the lymph 
Table III. Correlation of the proportion of positive expression of biological markers in the primary tumor and corresponding lymph node metastases $\left(n=43^{\mathrm{a}}\right)$.

\begin{tabular}{|c|c|c|c|c|}
\hline Markers & $\begin{array}{c}\text { Primary tumor } \\
\text { epithelium, no. }(\%)\end{array}$ & $\begin{array}{c}\text { Lymph node metastasis } \\
\text { epithelium, no. }(\%)\end{array}$ & $\begin{array}{l}\text { Primary tumor } \\
\text { stroma, no. }(\%)\end{array}$ & $\begin{array}{c}\text { Lymph node metastasis } \\
\text { stroma, no. }(\%)\end{array}$ \\
\hline \multicolumn{5}{|c|}{ c-MYC (cyt) } \\
\hline Negative & $0(0.0)$ & $0(0.0)$ & $2(4.7)$ & 8 (18.6) \\
\hline Positive & $43(100.0)$ & $41(100.0)$ & $41(95.3)$ & $35(81.4)$ \\
\hline P-value & \multicolumn{2}{|c|}{ NS } & \multicolumn{2}{|c|}{0.09} \\
\hline \multicolumn{5}{|c|}{ c-MYC (nuc) } \\
\hline Negative & $4(9.3)$ & $10(24.4)$ & $2(4.7)$ & $13(30.2)$ \\
\hline Positive & 39 (90.7) & $31(75.6)$ & $41(95.3)$ & $30(69.8)$ \\
\hline P-value & \multicolumn{2}{|c|}{0.08} & \multicolumn{2}{|c|}{0.003} \\
\hline \multicolumn{5}{|l|}{ p-mTOR } \\
\hline Negative & $21(50.0)$ & $9(47.4)$ & $24(55.8)$ & $16(80.0)$ \\
\hline Positive & $21(50.0)$ & $10(52.6)$ & $19(44.2)$ & $4(20.0)$ \\
\hline P-value & \multicolumn{2}{|c|}{1.00} & \multicolumn{2}{|c|}{0.09} \\
\hline \multicolumn{5}{|l|}{$\mathrm{p}-\mathrm{AKT}$} \\
\hline Negative & $12(27.9)$ & $2(10.5)$ & 15 (34.9) & $6(30.0)$ \\
\hline Positive & $31(72.1)$ & $17(89.5)$ & $28(65.1)$ & $14(70.0)$ \\
\hline P-value & \multicolumn{2}{|c|}{0.19} & \multicolumn{2}{|c|}{0.78} \\
\hline \multicolumn{5}{|l|}{ ER } \\
\hline Negative & $22(53.7)$ & $19(46.3)$ & $43(100.0)$ & $43(100.0)$ \\
\hline Positive & $19(46.3)$ & $22(53.7)$ & $0(0.0)$ & $0(0.0)$ \\
\hline P-value & \multicolumn{2}{|c|}{0.66} & & \\
\hline \multicolumn{5}{|l|}{ PR } \\
\hline Negative & $24(64.9)$ & $27(73.0)$ & $43(100.0)$ & $43(100.0)$ \\
\hline Positive & $13(35.1)$ & $10(27.0)$ & $0(0.0)$ & $0(0.0)$ \\
\hline P-value & \multicolumn{2}{|c|}{0.23} & & \\
\hline \multicolumn{5}{|l|}{ HER 2} \\
\hline Negative & $33(78.6)$ & $32(76.2)$ & $43(100.0)$ & $43(100.0)$ \\
\hline Positive & $9(21.4)$ & $10(23.8)$ & $0(0.0)$ & $0(0.0)$ \\
\hline P-value & \multicolumn{2}{|c|}{1.00} & & \\
\hline \multicolumn{5}{|l|}{ p53 } \\
\hline Negative & $30(73.2)$ & $29(69.0)$ & $43(100.0)$ & $43(100.0)$ \\
\hline Positive & $11(26.8)$ & $13(31.0)$ & $0(0.0)$ & $0(0.0)$ \\
\hline P-value & \multicolumn{2}{|c|}{0.81} & & \\
\hline \multicolumn{5}{|l|}{ Ki67 } \\
\hline Negative & $32(78.0)$ & $28(66.7)$ & $43(100.0)$ & $43(100.0)$ \\
\hline Positive & $9(22.0)$ & $14(33.3)$ & $0(0.0)$ & $0(0.0)$ \\
\hline P-value & \multicolumn{2}{|c|}{0.33} & & \\
\hline
\end{tabular}

Cyt, cytoplasmic; nuc, nuclear; NS, not significant; p-mTOR, phospho-mammalian target of rapamycin; p-AKT, phospho-AKT; ER, estrogen

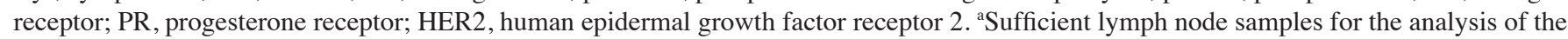
studied antibodies were not available from all 43 patients.

nodes is crucial for the development of more effective treatment strategies.

Previous investigators suggested a mechanism of dissemination of breast cancer cells from the primary tumor dictated by molecular changes that occur early during the course of tumorigenesis, which may be regulated by increased MYC expression, which indirectly affects the metastatic propensity of cancer cells through promoting proliferation and survival $(3,18)$. Stromal fibroblasts are designed to create an environment that promotes tumor progression (19). Moreover, there has been evidence that the proliferative activity and soluble factors secreted by stromal fibroblasts are closely associated with lymph node metastasis (20). In addition, a clear increase of MYC expression at the RNA and protein level 
Table IV. Correlation between biomarker expression in the epithelial component of the primary tumor and prognostic factors.

\begin{tabular}{|c|c|c|c|c|c|c|c|c|c|c|}
\hline \multirow{2}{*}{$\begin{array}{l}\text { Clinico- } \\
\text { pathological } \\
\text { data }\end{array}$} & \multicolumn{2}{|c|}{ c-MYC (cyt) } & \multicolumn{2}{|c|}{ c-MYC (nuc) } & \multicolumn{2}{|c|}{ Ki67 } & \multicolumn{2}{|c|}{ p-mTOR } & \multicolumn{2}{|c|}{$\mathrm{p}-\mathrm{AKT}$} \\
\hline & Negative & Positive & Negative & Positive & Negative & Positive & Negative & Positive & Negative & Positive \\
\hline \multicolumn{11}{|l|}{$\mathrm{HG}$} \\
\hline 1 & $1(50.0)$ & $16(20.8)$ & $3(30.0)$ & $14(20.3)$ & $15(26.3)$ & $0(0.0)$ & $7(17.0)$ & $10(26.3)$ & $2(11.8)$ & $16(25.4)$ \\
\hline 2,3 & $1(50.0)$ & $61(79.2)$ & $7(70.0)$ & $55(79.7)$ & $42(73.7)$ & $17(100.0)$ & $34(83.0)$ & $28(73.7)$ & $15(88.2)$ & $47(74.6)$ \\
\hline P-value & \multicolumn{2}{|c|}{0.38} & \multicolumn{2}{|c|}{0.44} & \multicolumn{2}{|c|}{0.02} & \multicolumn{2}{|c|}{0.41} & \multicolumn{2}{|c|}{0.33} \\
\hline \multicolumn{11}{|l|}{ LN status } \\
\hline Negative & $2(100.0)$ & $34(44.2)$ & $6(60.0)$ & $30(43.5)$ & 25 (43.9) & $8(47.1)$ & $20(48.8)$ & $17(44.7)$ & $5(29.4)$ & $32(50.8)$ \\
\hline Positive & $0(0.0)$ & $43(55.8)$ & $4(40.0)$ & $39(56.5)$ & $32(56.1)$ & $9(52.9)$ & $21(51.2)$ & $21(55.3)$ & $12(70.6)$ & $31(49.2)$ \\
\hline P-value & \multicolumn{2}{|c|}{0.20} & \multicolumn{2}{|c|}{0.50} & \multicolumn{2}{|c|}{1.0} & \multicolumn{2}{|c|}{0.82} & \multicolumn{2}{|c|}{0.17} \\
\hline \multicolumn{11}{|l|}{ Stage } \\
\hline I & $1(50.0)$ & $18(23.3)$ & $4(40.0)$ & $15(21.7)$ & $14(24.6)$ & 4 (23.6) & $14(34.1)$ & $6(15.8)$ & $1(5.9)$ & $19(30.2)$ \\
\hline II & $1(50.0)$ & $31(40.3)$ & $2(20.0)$ & $30(43.5)$ & $21(36.8)$ & $8(47.0)$ & $17(41.4)$ & $15(39.5)$ & $11(64.7)$ & $21(33.3)$ \\
\hline III & $0(0)$ & $28(36.4)$ & $4(40.0)$ & $24(34.8)$ & $22(38.6)$ & $5(29.4)$ & $10(24.4)$ & $17(44.7)$ & $5(29.4)$ & $23(36.5)$ \\
\hline P-value & \multicolumn{2}{|c|}{0.51} & \multicolumn{2}{|c|}{0.29} & \multicolumn{2}{|c|}{0.72} & \multicolumn{2}{|c|}{0.08} & \multicolumn{2}{|c|}{0.04} \\
\hline
\end{tabular}

Mitoses

$\begin{array}{lcccccccccc}0-5 & 1(50.0) & 30(39.0) & 3(30.0) & 28(40.6) & 27(47.3) & 2(11.8) & 14(34.1) & 17(43.6) & 3(17.6) & 29(46.0) \\ >5 & 1(50.0) & 47(61.0) & 7(70.0) & 41(59.4) & 30(52.7) & 15(88.2) & 27(65.9) & 21(56.4) & 14(82.4) & 34(54.0) \\ \text { P-value } & & 1.00 & & 0.73 & 0.01 & & 0.37 & & \\ \text { Necrosis } & & & & & & & & & \\ \text { Absent } & 1(50.0) & 35(45.5) & 2(20.0) & 34(49.3) & 27(47.4) & 8(47.1) & 18(43.9) & 19(50.0) & 7(41.2) & 30(47.6) \\ \text { Present } & 1(50.0) & 42(54.5) & 8(80.0) & 35(50.7) & 30(52.6) & 9(52.9) & 23(56.1) & 19(50.0) & 10(58.8) & 33(52.4) \\ \text { P-value } & & 1.00 & & 0.10 & 1.00 & 0.66 & 0.79 & \end{array}$

Margins

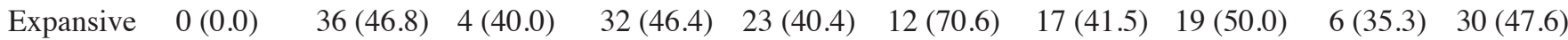

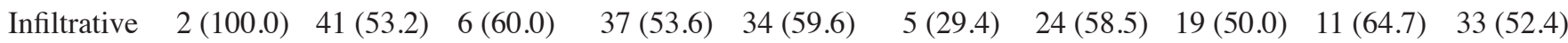
P-value 0.50 0.75 0.05 0.50 0.42

ER

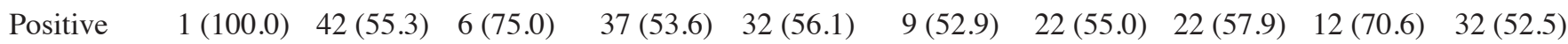

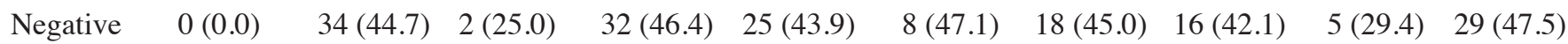
$\begin{array}{lllllll}\text { P-value } & 1.00 & 0.29 & 1.00 & 0.82 & 0.27\end{array}$

PR

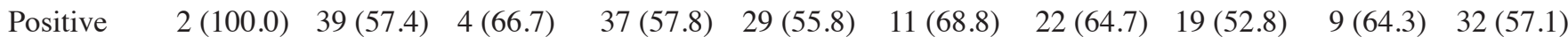

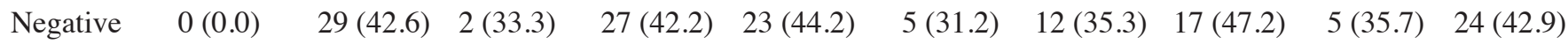
$\begin{array}{llllll}\text { P-value } & 0.51 & 1.00 & 0.40 & 0.34 & 0.76\end{array}$

HER2

$\begin{array}{lllllllllll}\text { Positive } & 2(100.0) & 58(77.3) & 8(100.0) & 52(75.4) & 44(78.6) & 13(76.5) & 31(77.5) & 30(78.9) & 13(76.5) & 48(78.7)\end{array}$

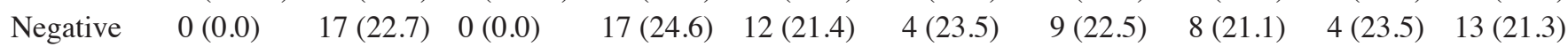
$\begin{array}{llllll}\text { P-value } & 1.00 & 0.18 & 1.00 & 1.00 & 1.00\end{array}$

Cyt, cytoplasmic; nuc, nuclear; p-mTOR, phospho-mammalian target of rapamycin; p-AKT, phospho-AKT; HG, histological grade; LN, lymph node; ER, estrogen receptor; PR, progesterone receptor; HER2, human epidermal growth factor receptor 2.

was detected in human telomerase-immortalized fibroblasts that gradually underwent neoplastic transformation (21). However, to the best of our knowledge, an assessment of MYC expression in CAFs located either in the primary tumor or in matched node metastasis in human breast cancer has not yet been performed.
In this study, we detected a high frequency of MYC expression (nuclear or cytoplasmic) in the epithelial and stromal components of either the primary tumors (the majority of which were high-grade) or the metastatic nodes harvested at initial surgery. Our results are in line with those of previous studies investigating MYC gene amplification or 
Table V. Distribution of protein expression pattern in the tumor epithelium according to molecular groups of invasive ductal carcinoma.

\begin{tabular}{|c|c|c|c|c|c|}
\hline Variables & $\begin{array}{c}\text { Luminal A } \\
\left(\mathrm{HER}^{-} / \mathrm{ER}^{+} \text {or } \mathrm{PR}^{+}\right) \\
\text {no. }(\%)\end{array}$ & $\begin{array}{c}\text { Luminal B } \\
\left(\mathrm{HER}^{+} / \mathrm{ER}^{+} \text {or } \mathrm{PR}^{+}\right) \\
\text {no. }(\%)\end{array}$ & $\begin{array}{c}\mathrm{HER}^{+} / \mathrm{ER}^{-} \text {and } \mathrm{PR}^{-} \\
\text {no. }(\%)\end{array}$ & $\begin{array}{c}\text { Triple-negative } \\
\text { no. }(\%)\end{array}$ & P-value \\
\hline c-MYC (cyt) & & & & & 0.30 \\
\hline Positive & $29(42.7)$ & $13(19.1)$ & $12(17.6)$ & $14(20.6)$ & \\
\hline Negative & $0(0.0)$ & $0(0.0)$ & $0(0.0)$ & $1(100.0)$ & \\
\hline c-MYC (nuc) & & & & & 0.13 \\
\hline Positive & $27(42.1)$ & $13(20.3)$ & $12(18.8)$ & $12(18.8)$ & \\
\hline Negative & $2(40.0)$ & $0(0.0)$ & $0(0.0)$ & $3(60.0)$ & \\
\hline p53 & & & & & 0.53 \\
\hline Positive & $7(31.8)$ & $4(18.2)$ & $6(27.3)$ & $5(22.7)$ & \\
\hline Negative & $20(44.5)$ & $9(20.0)$ & $6(13.3)$ & $10(22.2)$ & \\
\hline Ki67 & & & & & 0.001 \\
\hline Positive & $0(0.0)$ & $10(62.4)$ & $3(18.8)$ & $3(18.8)$ & \\
\hline Negative & $28(53.8)$ & $3(5.8)$ & $9(17.3)$ & $12(23.1)$ & \\
\hline p-mTOR & & & & & 0.16 \\
\hline Positive & $14(38.9)$ & $10(27.8)$ & $4(11.1)$ & $8(22.2)$ & \\
\hline Negative & $15(45.5)$ & $3(9.1)$ & $8(24.2)$ & $7(21.2)$ & \\
\hline $\mathrm{p}-\mathrm{AKT}$ & & & & & 0.44 \\
\hline Positive & $25(45.5)$ & $11(20.0)$ & $8(14.5)$ & $11(20.0)$ & \\
\hline Negative & $4(28.6)$ & $2(14.2)$ & $4(28.6)$ & $4(28.6)$ & \\
\hline
\end{tabular}

A two-sided $\mathrm{P}<0.05$ was considered statistically significant. ER, estrogen receptor; PR, progesterone receptor; HER2, human epidermal growth factor receptor 2; cyt, cytoplasmic; nuc, nuclear; p-mTOR, phospho-mammalian target of rapamycin; p-AKT, phospho-AKT.

protein overexpression in the epithelial component of breast cancer (6-9,22-24). However, we were unable to identify any correlation between MYC expression and axillary lymph node positivity in our series, confirming the results of previous studies $(5,6,25)$. Although MYC stimulates cell proliferation, which is generally associated with more aggressive cancer phenotypes, playing an important role in cancer progression (3), in our analysis, MYC was not found to be associated with either Ki67 or number of mitoses in the epithelial cells of the primary tumors. MYC was also not found to be associated with proliferation markers, such as p-AKT and p-mTOR. As regards other markers, nuclear MYC was found to be associated with p53 $(\mathrm{P}=0.048)$, which in turn was found to be associated with $\mathrm{Ki} 67(\mathrm{P}=0.045)$. The combination of non-functional p53 and increased MYC expression may be responsible for the increased proliferation of the epithelial cells of the primary tumors (26).

A number of laboratory studies have demonstrated an estrogen-dependent expression of MYC in cell models of $\mathrm{ER}^{+}$ breast cancer (8) and prior reports have identified a significant overlap in estrogen- and MYC-responsive genes, the majority of which are actively involved in cell growth (27). In accordance, published literature suggests that MYC protein expression in carcinomas may be predictive of resistance to hormone therapy (28). Todorović-Raković et al (6) described an association between MYC amplification and positive ER expression, which our data of MYC expression did not confirm. However, our study demonstrated that, despite MYC expression spanning accross all the intrinsic subtypes of breast cancer determined in our primary and metastatic samples, there was a tendency toward a higher MYC positivity rate in the luminal subtype, as compared to the other subtypes, although this tendency was not statistically significant $(\mathrm{P}=0.13)$. This result contradicts those of other studies demonstrating a clear association between MYC amplification and ER-negative or basal breast cancers $(9,29-31)$. It is possible that, in luminal A tumors displaying low Ki67 scores, MYC expression reflects biological characteristics of the tumor cell population other than its proliferative state. Evidence has been provided supporting that MYC may be required for the post-transcriptional accumulation of hypoxia-inducible factor $\alpha$ protein in $\mathrm{MCF} 7\left(\mathrm{ER}^{+}\right)$ breast cancer cells, leading to metabolic advantages regarding cancer cell survival (32).

Our results have documented MYC expression, as well as mTOR and p-AKT expression, not only in tumor epithelial cells, but also in the fibroblasts associated with the primary breast tumors and nodal metastases. Baudino et al (33) previously demonstrated in mouse models that MYC is a key regulator of several cytokines involved in lymphangiogenesis, such as vascular endothelial growth factor (VEGF)-C and VEGF-D, suggesting that increased expression of MYC may provide a selective advantage for the development of nodal 
Table VI. Association between primary tumor marker expression in the epithelial component of invasive ductal breast carcinoma.

\begin{tabular}{|c|c|c|c|c|c|c|c|c|}
\hline Variables & c-MYC (nuc) & mTOR & $\mathrm{p}-\mathrm{AKT}$ & p53 & ER & PR & HER2 & Ki67 \\
\hline \multicolumn{9}{|c|}{ c-MYC (cyt) } \\
\hline $\mathrm{R}$ & 0.181 & 0.158 & 0.112 & 0.084 & 0.102 & 0.144 & 0.087 & 0.064 \\
\hline P-value & 0.110 & 0.167 & 0.327 & 0.479 & 0.377 & 0.234 & 0.452 & 0.588 \\
\hline \multicolumn{9}{|c|}{ c-MYC (nuc) } \\
\hline $\mathrm{R}$ & & 0.111 & -0.107 & 0.231 & 0.131 & 0.050 & 0.181 & 0.067 \\
\hline $\mathrm{P}$-value & & 0.333 & 0.349 & 0.048 & 0.255 & 0.679 & 0.115 & 0.572 \\
\hline \multicolumn{9}{|l|}{ mTOR } \\
\hline $\mathrm{R}$ & & & 0.134 & -0.029 & -0.029 & 0.121 & -0.018 & 0.175 \\
\hline P-value & & & 0.238 & 0.809 & 0.800 & 0.318 & 0.879 & 0.135 \\
\hline \multicolumn{9}{|l|}{$\mathrm{p}-\mathrm{AKT}$} \\
\hline $\mathrm{R}$ & & & & -0.041 & 0.151 & 0.058 & -0.022 & 0.053 \\
\hline P-value & & & & 0.727 & 0.187 & 0.633 & 0.847 & 0.655 \\
\hline \multicolumn{9}{|l|}{ p53 } \\
\hline $\mathrm{R}$ & & & & & -0.047 & -0.077 & 0.080 & 0.235 \\
\hline $\mathrm{P}$-value & & & & & 0.692 & 0.536 & 0.499 & 0.045 \\
\hline \multicolumn{9}{|l|}{ ER } \\
\hline $\mathrm{R}$ & & & & & & 0.327 & -0.347 & 0.027 \\
\hline P-value & & & & & & 0.006 & 0.002 & 0.819 \\
\hline \multicolumn{9}{|l|}{ PR } \\
\hline $\mathrm{R}$ & & & & & & & -0.251 & -0.112 \\
\hline P-value & & & & & & & 0.036 & 0.364 \\
\hline \multicolumn{9}{|l|}{ HER 2} \\
\hline $\mathrm{R}$ & & & & & & & & 0.021 \\
\hline P-value & & & & & & & & 0.857 \\
\hline
\end{tabular}

Bold print denotes statistical significance. A negative Spearman's rank test value $(\mathrm{R})$ indicates an inverse correlation. Two-sided $\mathrm{P}<0.05$ was considered statistically significant. Nuc, nuclear; cyt, cytoplasmic; p-AKT, phospho-AKT; ER, estrogen receptor; PR, progesterone receptor; HER2, human epidermal growth factor receptor 2.

metastases. Fibroblasts expressing MYC may act locally at the metastatic site to facilitate colonization via the establishment of a lymphangiogenic microenvironment to support cancer survival. Moreover, a number of glucose metabolism-related genes were found to be directly regulated by MYC (34) and fibroblasts were reported to exhibit increased expression of glycolytic enzymes that may be utilized by adjacent cancer cells to facilitate growth and angiogenesis (35).

Several studies have addressed the differences in the expression of individual breast cancer markers, including ER, PR, HER2, p53 and Ki67, as well as other markers, between primary breast tumors and metastases derived from the same patient; however, the discordant rates varied widely accross studies $(8,36,37)$. In line with previous publications, we did not identify statistically significant discordant expression for any of the classical biomarkers analyzed (ER, PR, p53, Ki67 and HER2), or for the proliferative markers p-mTOR and p-AKT.

However, in nodal metastases, we observed a trend for reduced frequency of nuclear MYC expression in epithelial cells as compared to those of the primary tumors $(\mathrm{P}=0.08)$. In the lymph node stroma, of the 43 matched pairs, $25.5 \%$ had discordant immunohistochemical results and this decrease was statistically significant $(\mathrm{P}=0.003)$. There is currently no explanation regarding the significance of this finding. We may hypothesize that the reduced MYC expression frequency between primary tumors and nodal metastases in both components may reflect an adaptation to a different environment in the lymph node tissue.

In conclusion, MYC is frequently expressed in breast cancer and its expression is maintained in lymph node metastasis. Tumor stromal cells actively express MYC, either in the primary or the metastatic tumor sites. Furthermore, epithelial and stromal cells in nodal metastases exhibit similar but discretely distinct MYC expression patterns.

In conclusion, MYC expression, although highly prevalent, was not found to be correlated with breast cancer proliferation markers, such as Ki67, p-mTOR, p-AKT, p53 and EGFR, classical predictive markers, such as ER, PR and HER2, or molecular subtypes, suggesting that MYC may be involved in other pathways. Fibroblasts expressing MYC may act at the primary or metastatic site by establishing a lymphangiogenic microenvironment to optimize cancer cell survival. Our results, indicating subtle differences among the biomarkers analyzed between primary tumors and matched nodal 
metastases, suggest that the development of nodal metastasis may be a gradual process.

\section{Acknowledgements}

This study was supported by FAPESP (grant no. 09/10088-7).

\section{References}

1. Albihn A, Johnsen JI and Henriksson MA: MYC in oncogenesis and as a target for cancer therapies. Adv Cancer Res 107: 163-224, 2010.

2. Chen Y and Olopade OI: MYC in breast tumor progression. Expert Rev Anticancer Ther 8: 1689-1698, 2008.

3. Wolfer A and Ramaswamy S: MYC and metastasis. Cancer Res 71: 2034-2037, 2011.

4. Wolfer A, Wittner BS, Irimia D, et al: MYC regulation of a 'poor-prognosis' metastatic cancer cell state. Proc Natl Acad Sci USA 107: 3698-3703, 2010.

5. Rodriguez-Pinilla SM, Jones RL, Lambros MB, et al: MYC amplification in breast cancer: a chromogenic in situ hybridisation study. J Clin Pathol 60: 1017-1023, 2007.

6. Todorović-Raković N, Nešković-Konstantinović Z and Nikolić-Vukosavljević D: C-myc as a predictive marker for chemotherapy in metastatic breast cancer. Clin Exp Med 12: 217-223, 2012

7. Joensuu K, Hagström J, Leidenius M, Haglund C, Andersson LC, Sariola $\mathrm{H}$ and Heikkilä P: Bmi-1, c-myc, and Snail expression in primary breast cancers and their metastases - elevated Bmi-1 expression in late breast cancer relapses. Virchows Arch 459 31-39, 2011.

8. Planas-Silva MD, Bruggeman RD, Grenko RT and Smith JS: Overexpression of c-Myc and Bcl-2 during progression and distant metastasis of hormone-treated breast cancer. Exp Mol Pathol 82: 85-90, 2007.

9. Singhi AD, Cimino-Mathews A, Jenkins RB, et al: MYC gene amplification is often acquired in lethal distant breast cancer metastases of unamplified primary tumors. Mod Pathol 25: 378-387, 2012.

10. Kalluri R and Zeisberg M: Fibroblasts in cancer. Nat Rev Cancer 6: 392-401, 2006.

11. Gouvêa AP, Milanezi F, Olson SJ, Leitao D, Schmitt FC and Gobbi H: Selecting antibodies to detect HER2 overexpression by immunohistochemistry in invasive mammary carcinomas. Appl Immunohistochem Mol Morphol 14: 103-108, 2006.

12. Allred DC and Elledge RM: Caution concerning micrometastatic breast carcinoma in sentinel lymph nodes. Cancer 86: 905-907, 1999.

13. Nielsen TO, Hsu FD, Jensen K, et al: Immunohistochemical and clinical characterization of the basal-like subtype of invasive breast carcinoma. Clin Cancer Res 10: 5367-5374, 2004.

14. Carey LA, Perou CM, Livasy CA, et al: Race, breast cancer subtypes, and survival in the Carolina Breast Cancer Study. JAMA 295: 2492-2502, 2006.

15. Tobler NE and Detmar M: Tumor and lymph node lymphangiogenesis - impact on cancer metastasis. J Leukoc Biol 80: 691-696, 2006 .

16. Cao Y: Opinion: emerging mechanisms of tumour lymphangiogenesis and lymphatic metastasis. Nat Rev Cancer 5: 735-743, 2005 .

17. Chambers AF, Groom AC and MacDonald IC: Dissemination and growth of cancer cells in metastatic sites. Nat Rev Cancer 2: 563-572, 2002

18. Ellsworth RE, Ellsworth DL, Patney HL, Deyarmin B, Hooke JA, Love B and Shriver CD: Genomic alterations associated with early stages of breast tumor metastasis. Ann Surg Oncol 15: 1989-1995, 2008.
19. O'Connell JT, Sugimoto H, Cooke VG, et al: VEGF-A and tenascin-C produced by $\mathrm{S} 100 \mathrm{~A} 4^{+}$stromal cells are important for metastatic colonization. Proc Natl Acad Sci USA 108 : 16002-16007, 2011.

20. Hasebe T, Sasaki S, Imoto S and Ochiai A: Proliferative activity of intratumoral fibroblasts is closely correlated with lymph node and distant organ metastases of invasive ductal carcinoma of the breast. Am J Pathol 156: 1701-1710, 2000.

21. Ostano P, Bione S, Belgiovine C, et al: Cross-analysis of gene and miRNA genome-wide expression profiles in human fibroblasts at different stages of transformation. OMICS 16: 24-36, 2012.

22. Chrzan P, Skokowski J, Karmolinski A and Pawelczyk T: Amplification of $\mathrm{c}-\mathrm{myc}$ gene and overexpression of $\mathrm{c}-\mathrm{Myc}$ protein in breast cancer and adjacent non-neoplastic tissue. Clin Biochem 34: 557-562, 2001

23. Blancato J, Singh B, Liu A, Liao DJ and Dickson RB: Correlation of amplification and overexpression of the c-myc oncogene in high-grade breast cancer: FISH, in situ hybridisation and immunohistochemical analyses. Br J Cancer 90: 1612-1619, 2004.

24. Naidu R, Wahab NA, Yadav M and Kutty MK: Protein expression and molecular analysis of c-myc gene in primary breast carcinomas using immunohistochemistry and differential polymerase chain reaction. Int J Mol Med 9: 189-196, 2002.

25. Spandidos DA, Yiagnisis M, Papadimitriou K and Field JK: ras, c-myc and c-erbB-2 oncoproteins in human breast cancer. Anticancer Res 9: 1385-1393, 1989.

26. Zongaro S, de Stanchina E, Colombo T, D'Incalci M, Giulotto E and Mondello C: Stepwise neoplastic transformation of a telomerase immortalized fibroblast cell line. Cancer Res 65: 11411-11418, 2005.

27. Musgrove EA, Sergio CM, Loi S, et al: Identification of functional networks of estrogen- and c-Myc-responsive genes and their relationship to response to tamoxifen therapy in breast cancer. PLoS One 3: e2987, 2008.

28. Miller TW, Balko JM, Ghazoui Z, et al: A gene expression signature from human breast cancer cells with acquired hormone independence identifies MYC as a mediator of antiestrogen resistance. Clin Cancer Res 17: 2024-2034, 2011.

29. Chandriani S, Frengen E, Cowling VH, Pendergrass SA, Perou CM, Whitfield ML and Cole MD: A core MYC gene expression signature is prominent in basal-like breast cancer but only partially overlaps the core serum response. PLoS One 4: e6693, 2009.

30. Yasojima H, Shimomura A, Naoi Y, et al: Association between c-myc amplification and pathological complete response to neoadjuvant chemotherapy in breast cancer. Eur J Cancer 47: 1779-1788, 2011.

31. Alles MC, Gardiner-Garden M, Nott DJ, et al: Meta-analysis and gene set enrichment relative to ER status reveal elevated activity of MYC and E2F in the 'basal' breast cancer subgroup. PLoS One 4: e4710, 2009.

32. Doe MR, Ascano JM, Kaur M and Cole MD: Myc posttranscriptionally induces HIF1 protein and target gene expression in normal and cancer cells. Cancer Res 72: 949-957, 2012.

33. Baudino TA, McKay C, Pendeville-Samain H, et al: c-Myc is essential for vasculogenesis and angiogenesis during development and tumor progression. Genes Dev 16: 2530-2543, 2002.

34. Dang CV, Le A and Gao P: MYC-induced cancer cell energy metabolism and therapeutic opportunities. Clin Cancer Res 15: 6479-6483, 2009.

35. Pavlides S, Whitaker-Menezes D, Castello-Cros R, et al: The reverse Warburg effect: aerobic glycolysis in cancer associated fibroblasts and the tumor stroma. Cell Cycle 8: 3984-4001, 2009.

36. Falck AK, Fernö M, Bendahl PO and Rydén L: Does analysis of biomarkers in tumor cells in lymph node metastases give additional prognostic information in primary breast cancer? World J Surg 34: 1434-1441, 2010.

37. Aitken SJ, Thomas JS, Langdon SP, Harrison DJ and Faratian D: Quantitative analysis of changes in ER, PR and HER2 expression in primary breast cancer and paired nodal metastases. Ann Oncol 21: 1254-1261, 2010. 